\title{
Development of a Customized Integrated Waste Management Environmental Assessment (IWMEA) Model for Life Cycle Assessment (LCA) Of Solid Wastes
}

\author{
${ }^{1}$ I.O Olawoore, ${ }^{2}$ A.A Adegbola, ${ }^{3}$ S.O Ojoawo, ${ }^{4}$ O.S Olaniyan \\ ${ }^{1,2,3,3}$ Department of Civil Engineering, Ladoke Akintola University of Technology,P.M.B 4000, Ogbomoso,
} Nigeria.

\begin{abstract}
This research centers on the development and application of a customized integrated waste management environmental assessment (IWMEA) modeling tool for developing countries. A prime objective is to evolve an effective Solid Waste Management (SWM) scheme which meets cost, energy, and safe environmental emissions. SWM system consisting of several unit processes which includes collection, transfer, sorting, treatment (e.g. combustion, composting, recycling), and final disposal. In the study, waste is categorized into 48 items and their generation rates are defined for three types of sectors: single-family dwelling, multi-family dwelling, and commercial. The mass flow of each item through all possible combinations of unit processes is represented in a linear programming model using a unique modeling approach. Cost, energy consumption, and environmental emissions associated with waste processing at each unit process are computed in a set of specially implemented unit model. The Life Cycle Assessment approach is used to compute energy consumption and emissions of $\mathrm{CO}$, fossil-fuel, and biomass-derived $\mathrm{CO}_{2}, \mathrm{NO}_{x}, \mathrm{SO}_{x}$, particulate matter, $P M_{10}$ and greenhouse gases. A fuzzy multi-criteria decision support tool called IWMEA model for environmental assessment of integrated waste was developed.

Four different scenarios of waste management systems were considered. These are: scenario one where all wastes (100,000 tonnes) landfilled; scenario two is 25\% (25,000 tonnes) recycled, and the rest landfilled. In scenario three, we have 25\% recycled, $20 \%$ composted and $55 \%$ landfilled; the last scenario has 25\% recycled, 20\% composted, 25\% Energy From Waste (EFW), and the remaining landfilled. Results show that the energy saving with the scenarios are: $+6978 ;-366,028 ;-366,963$ and $-545,407$ GJ respectively. There was more reduction of greenhouse gases in scenario four as compared with others. However, there was more reduction of acid gases in scenario two in relation to others. Moreso, the reduction in heavy metals concentration was more pronounced in scenario three with respect to the rest scenarios. Economically, the fourth scenario was the best in term of cost, energy saving and greenhouse gas emission. It is therefore recommended for application in developing countries.
\end{abstract}

Keywords: Life Cycle Assessment, IWMEA model, Solid Waste Management, Energy saving, Greenhouse gases

\section{Introduction}

The protection of the environment and natural resources is increasingly becoming very important through environmentally sustainable waste management programs. It is necessary to follow, on the part of waste managers, a sustainable approach to waste management and to integrate strategies that will produce the best practicable option. This is a very challenging task since it involves taking into account economic, technical, regulatory (normative), and environmental issues (Costi, Minciardi, et al, 2004). Waste management can become more complex if social and political considerations are also taken into account. Municipal solid waste (MSW) management involves the collection of waste from its sources and the transportation of waste to processing plants where it can either be converted into fuel (refuse derived fuel), electrical energy, compost (stabilised organic material) or recycled for reuse. The unrecoverable waste can either be transported directly from the waste sources to landfills or from treatment plants to landfills. A careful planning is required in order to execute these activities in an optimal way. Municipal solid waste has several sources such as residential areas, commercial areas, institutional environments, construction and demolition areas, municipal services, etc. (Badran and El-Haggar, 2006). The effective application of SWM mathematical models as tools for decision making by municipal solid waste planners, in developing countries, is still a big challenge. A considerable amount of research has been done in the last two decades on various aspects of SWM, and a number of economically based optimization models for waste streams allocation and collection vehicle routes, have been developed (Chang, Chen et al, 1997). Owing to an increasing awareness of environmental protection and conservation of natural resources, rising prices of raw materials, and energy conservation concerns, the current research in SWM is now guided by the aim of designing comprehensive models that take into account multidisciplinary aspects involving economic, technical, regulatory, and environmental sustainability issues. 
Life cycle assessment (LCA), which is used to assess the environmental impacts of products from cradle to grave, is increasingly being applied to the evaluation of waste management strategies. Life cycle analysis offers a holistic and objective basis for comparing alternative systems (Aumonier, 1995). It should be noted however that there is a fundamental difference between the life cycle boundaries of products and wastes. The life cycle of a product starts with the extraction of raw materials (through activities such as mining, logging, etc) and ends with the final disposal of a product. Caruso, Colorni, et al (1993), the life cycle of a waste on the other hand, starts when a material is discarded into the waste stream and ends when the waste material has either been converted into a resource (such as recycled material or recovered energy) or, when it has been finally disposed.

According to Olawoore et.al (2011), life cycle assessments are generally defined as consisting of four phases: goal definition and scoping;

i. inventory analysis whereby the resources consumed and pollutants released over the defined life cycle of a product or service are inventoried;

ii. impact analysis whereby the inventoried parameters are aggregated to produce a overall indication of environmental impact; and,

iii. interpretation analysis, whereby the significance and relevance of results of the inventory and/or impact analysis are used to improve the environmental performance of the system.

Over the last few years, agencies such as the Society of Environmental Toxicology and Chemistry (1991), and the International Standards Organisation (ISO) have undertaken the development of standardized methodologies for conducting LCAs. As a result of these efforts, there is now broad agreement on a methodology for carrying out the first two phases of life cycle assessments - goal definition and scoping and life cycle inventories (LCI). The third and the fourth phase of life cycle assessments, impact analysis, is intrinsically more problematic and there is, at this time, no widely accepted methodology for combining the diverse environmental effects into a single measure of environmental performance. The scope of this study is therefore limited to an inventory of selected environmental parameters considered to be indicators of major environmental impact categories and an interpretation of the inventory results. A comprehensive treatment of the environmental effects of managing all materials in the waste stream by all available waste management options was not possible for practical limitations. The scope of the environmental analysis model was therefore defined to include the major components of residential waste: paper, plastic, glass, aluminum, steel, and food and yard waste. Each of these materials can potentially be managed by several different elements of an integrated waste management system and would therefore benefit from a systematic evaluation of management options.

Table 1: Waste Material/Waste Management Practice Combinations Evaluated by the Model

\begin{tabular}{|l|c|c|c|c|c|c|}
\hline Material & Recycling & Composting & $\begin{array}{c}\text { Anaerobic } \\
\text { Digestion }\end{array}$ & $\begin{array}{c}\text { Land } \\
\text { Application }\end{array}$ & $\begin{array}{c}\text { Energy } \\
\text { From } \\
\text { Waste }\end{array}$ & Landfilling \\
\hline Plastics & $\mathrm{Y}$ & & & & $\mathrm{Y}$ & $\mathrm{Y}$ \\
Aluminum & $\mathrm{Y}$ & & & & $\mathrm{Y}$ & $\mathrm{Y}$ \\
Ferrous & $\mathrm{Y}$ & & & & $\mathrm{Y}$ & $\mathrm{Y}$ \\
Metals & $\mathrm{Y}$ & & & & $\mathrm{Y}$ & $\mathrm{Y}$ \\
Glass & $\mathrm{Y}$ & & $\mathrm{Y}$ & & $\mathrm{Y}$ & $\mathrm{Y}$ \\
Paper & $\mathrm{Y}$ & $\mathrm{Y}$ & $\mathrm{Y}$ & $\mathrm{Y}$ & $\mathrm{Y}$ & $\mathrm{Y}$ \\
Yard & & $\mathrm{Y}$ & $\mathrm{Y}$ & & $\mathrm{Y}$ & $\mathrm{Y}$ \\
Waste & & $\mathrm{Y}$ & $\mathrm{Y}$ & & $\mathrm{Y}$ & $\mathrm{Y}$ \\
Food & & & & & & \\
Waste & & & & & & \\
Other & & & & & \\
Waste* & & & & &
\end{tabular}

(Source: Olawoore, et. al 2011)

In the environmental analysis model, miscellaneous materials such as textiles, diapers, kitty litter, home renovation wastes, rubber, leather, etc., are treated as a single category labeled 'other waste'. The 'other waste' category can only be taken through the energy recovery and landfilling options. During the goal and scope definition stage, it was further decided to address the environmental effects of managing each of these materials by recycling, composting, anaerobic digestion, energy recovery (where applicable) and/or landfilling. Table 1 above shows the material/waste management practice combinations that can be evaluated by the environmental analysis model. In the system boundaries, the life cycle of a waste begins when a product is discarded into the waste stream and ends when the waste material has either been converted into a resource (recycled material or recovered energy) or, when it has been finally disposed. Recovery processes such as recycling, energy recovery, 
composting and anaerobic digestion which result in the production of a usable material can be viewed as fulfilling two functions: the management of waste and, the production of useful material or energy (Environmental Canada, 1994; Environmental Agency, 2000). The life cycle boundaries for each of the waste management processes evaluated by the model are described below. The system boundary for the environmental analysis model is shown in Figure 1.

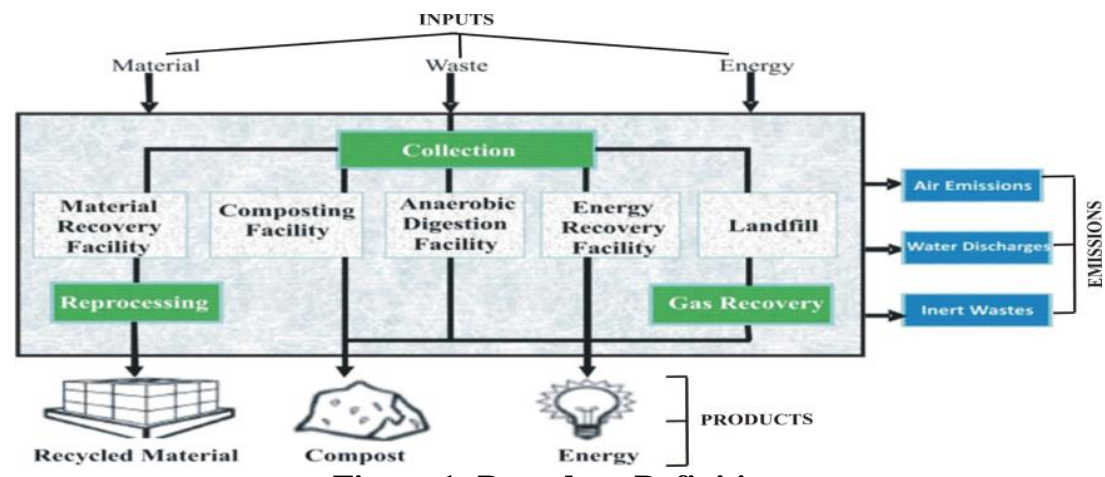

Figure 1: Boundary Definition

The system boundary for recycling used in the environmental analysis model starts at the point at which a recyclable is set out at the curb for collection and ends when a recycled material (which can be used as a substitute for a conventional material) is produced. For composting, the system boundary for composting extends from the collection of organics at the curb to the production of usable compost. The boundary for anaerobic digestion extends from the collection of organics or co-mingled wastes at the curbside through to the production of products including - heat and electrical energy and compost. Secondary materials are sent to an MRF for further processing, residues are sent to landfill and emissions are discharged into the atmosphere and hydrosphere. System boundaries for energy recovery processes evaluated in this model (direct energy recovery or landfill gas utilization) have been drawn from the point at which wastes are collected at the curb to the point at which recovered energy is produced. Energy and emissions associated with the production of conventional energy (e.g. fossil fuels) that can potentially be replaced by the recovered material and energy are also estimated and accounted for as avoided emissions (U.S EPA, 1979; U.S. EPA, 1993; U.S. EPA, 1995). Unlike emissions from other waste management processes, emissions from landfills occur over very long periods of time, spanning hundreds of years. In theory, the landfill is part of the evaluated system when it is environmentally active (producing leachate and gas), but reverts to becoming a part of the environment when its active life is over. Defining the active life of a landfill is difficult.

According to Olawoore et. al, 2011, in establishing inventories of greenhouse gases the IPCC Guidelines for Natural Greenhouse Gas Inventories was used. $\mathrm{CO}_{2}$ emissions from biogenic sources are not to be counted on the basis that the materials were originally grown by photosynthesis and during natural decay

would have simply closed the loop of the carbon cycle with the release of the $\mathrm{CO}_{2}$ back to atmosphere. In MSW typical materials for which $\mathrm{CO}_{2}$ emissions are not counted include papers, yard trimmings and food wastes. Thus for compost operations containing such materials the $\mathrm{CO}_{2}$ emissions would be zero. $\mathrm{CO}_{2}$ emissions arising from the combustion of fossil fuels such as by trucks hauling the above-noted materials to a compost operation would be counted. $\mathrm{CH}_{4}$ emissions from landfills are counted as though the source of the carbon is mainly biogenic. The rationale being that the $\mathrm{CH}_{4}$ is created and emitted as a result of human activity. If the $\mathrm{CH}_{4}$ emitted from a landfill is recovered as biogas and then either flared or combusted in an energy-producing apparatus the resultant $\mathrm{CO}_{2}$ which is produced is not counted. Only the $\mathrm{CH}_{4}$ emitted from uncontrolled landfills is counted (Chang and Wang, 1996). With respect to anaerobic digestion, all the $\mathrm{CH}_{4}$ produced is typically combusted and so the resultant $\mathrm{CO}_{2}$ emissions are not counted. In both the landfilling and anaerobic digestion operations just as described for composting, $\mathrm{CO}_{2}$ emissions from the consumption of fossil fuels while operating process equipment are always counted (McDougall, White $\mathrm{et} \mathrm{al,2001).}$

As a functional unit, the environmental analysis model evaluates energy/emissions from a userspecified quantity and composition of waste. This is therefore the functional unit for the model. The inventory results can be converted into burdens per tonne of MSW if, for example, the user would like to compare the environmental effects of managing one tonne of MSW by one waste management options vs. another (e.g. recycling vs. landfill). It should be noted however, that the comparison of energy/emissions per tonne amongst different jurisdictions can be misleading as it does not take into account the potential difference in the composition of that tonne.

The aim of this paper is to design a customized environmental assessment model tool for integrated waste management. The objectives are to provide Nigerian municipalities with a tool that would enable them to 
Development of a Customized Integrated Waste Management Environmental Assessment (Iwmea) evaluate the environmental performance of the various elements of their existing or proposed waste management systems and to compare different scenarios of environmental waste management using the model.

\subsection{IWMEA Model}

II. Methodology

Data on emissions from waste management processes are available to different levels depending on the extent of regulation of the process. For example, extensive data is available on emissions from waste incineration, and to a lesser extent, on landfilling. On the other hand, until recently relatively little data has been available on recycling and composting processes and even less for anaerobic digestion.

Efforts have been made to use the best data publicly available. In recent years, Ministry of Environment of the United States has undertaken a number of studies that have characterized the energy consumed and the emissions from waste management processes. In addition, the U.S. EPA, Environmental Canada and the UK Environment Agency have developed databases on emissions from waste management processes as part of their on-going waste LCA projects. This model has drawn extensively upon these data sources in developing default values and databases of emission factors for use in the analysis.

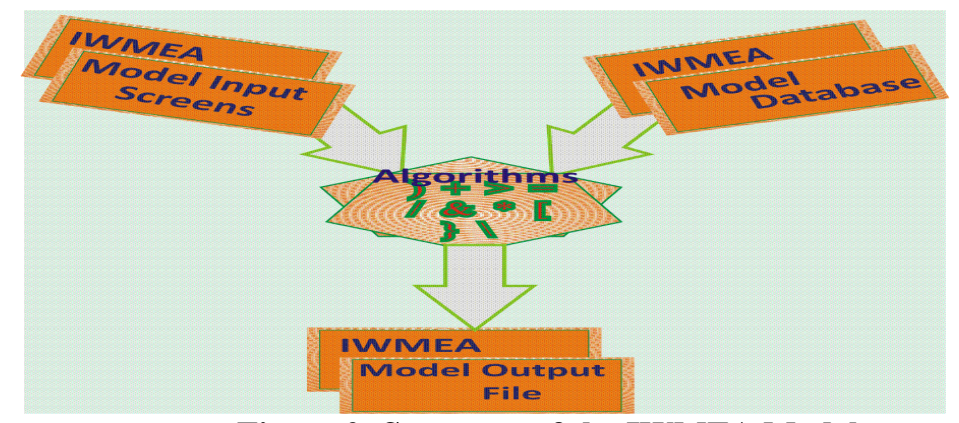

Figure 2: Structure of the IWMEA Model

Source: Olawoore, et. al 2011

The model is intended to be a living tool, and can be updated on a regular basis to incorporate newer and better data, as they become available. The data used within the model have been selected on the basis of the reliability of the source(s), age of the data and their applicability to Nigerian industry and practice. The environmental life cycle inventory model is an Excel 2000 TM model (with all the patches applied) with a Visual Basic graphical interface. The structure of the model is depicted graphically in Figure 2.

\subsection{Selected Environmental Parameters}

The environmental analysis tool estimates the amount of energy consumed (or produced) and the emissions to air, water and land associated with recycling, composting, energy from waste and landfilling. The environmental parameters selected for evaluation are shown in Table 2. Energy consumption was selected as an indicator of resource depletion.

Table 2: Selected Environmental Parameters

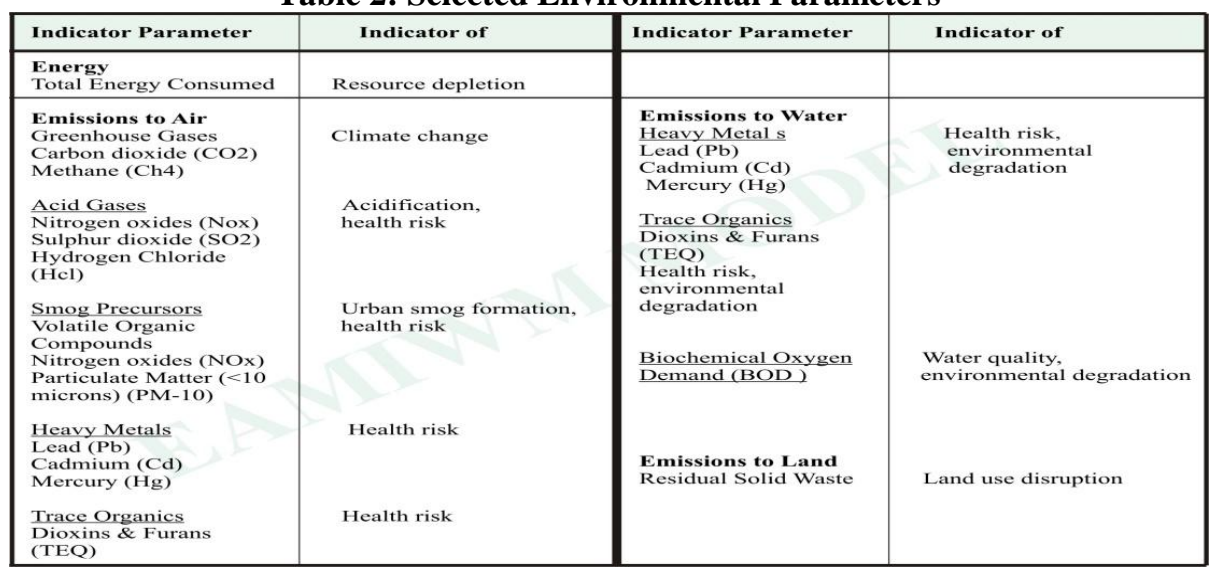

Source: Olawoore, et. al 2011

\subsection{Country Specific Data Requirements}


The IWMEA Model was designed initially for studying waste management practices across Nigeria. Through modifications to the default data sets it can be adopted for use in other countries. When reviewing the data requirements that are required to complete an analysis of a waste management system three classes of data need to be considered whenever the model is used outside Nigeria. The first are the user-input values which are requested each time the model is run and such values are germane to the municipality under study. The second are the default values. Each default value has been provided to assist the user to complete data entry and thereby allow the model to run. Each default value can be overwritten whenever a user has more up-to-date data.

The default values are based mainly on studies conducted throughout Nigeria. Examples include waste composition, energy values consumed by collection diesel trucks, energy consumed by waste processing operations and emission factors for the discharge of contaminants to both the atmosphere and hydrosphere as arising from energy from waste plants or landfilling operations, etc. The third categories are the module specific or hidden data sets which for the most part are not available to the user to modify. These data sets are essential for the operation of the model. Some examples include the energy consumed and emissions associated with the production of both virgin and recycled commodities. These include plastics, glass, steel, aluminum and paper products, energy production and related emissions for fossil fuels and electricity, etc. The values for this third category are country-specific and often present a significant challenge in acquiring. In the absence of countryspecific data, and provided sufficient documentation accompanies the model so as to ensure transparency, data from other countries may suffice.

\subsection{Derivation of Impact Equivalents}

Impact equivalents or conversion factors that would allow users to convert the inventory results into every day equivalents were developed for each environmental parameter evaluated by the model. The impact equivalents derived are shown in Table 3.

Table 3: Impact Equivalents and Conversion Factors

\begin{tabular}{|l|l|l|}
\hline Parameter & Impact Equivalent & Conversion Factor \\
\hline Energy & Power to supply x homes for one year & $34.22 \mathrm{GJ} / \mathrm{home} /$ year \\
Greenhouse Gases & Emissions from x vehicles for one year & $3.5 \mathrm{t} \mathrm{CO} / \mathrm{vehicle} / \mathrm{year}$ \\
Nitrogen Oxides & Emissions from x vehicles for one year & $19.7 \mathrm{~kg}$ NOx/vehicle/year \\
Sulphur Oxides & Power to supply x homes for one year & $6.2 \mathrm{~kg} \mathrm{SOx} / \mathrm{home} / \mathrm{year}$ \\
Hydrogen Chloride & Power to supply x homes for one year & $0.34 \mathrm{~kg} / \mathrm{home} / \mathrm{year}$ \\
Particulate Matter & Power to supply x homes for one year & $3.6 \mathrm{~kg} / \mathrm{home} /$ year \\
Volatile Organic Cmpds & Emissions from x vehicles for one year & $25.6 \mathrm{~kg} / \mathrm{vehicle} / \mathrm{year}$ \\
Lead (Air) & Power to supply x homes for one year & $0.3 \mathrm{~g} / \mathrm{home} /$ year \\
Mercury (Air) & Power to supply x homes for one year & $0.05 \mathrm{~g} / \mathrm{home} /$ year \\
Cadmium (Air) & Power to supply x homes for one year & $0.016 \mathrm{~g} / \mathrm{home} /$ year \\
Dioxins (TEQ) (Air) & Power to supply x homes for one year & $0.058 \mathrm{ug} / \mathrm{home} / \mathrm{year}$ \\
Lead (Water) & Power to supply x homes for one year & $8.5 \mathrm{~g} / \mathrm{home} /$ year \\
Mercury (Water) & Power to supply x homes for one year & $2.1 \mathrm{mg} / \mathrm{home} /$ year \\
Cadmium (Water) & Power to supply x homes for one year & $0.07 \mathrm{~g} / \mathrm{home} /$ year \\
BOD & Sewage from x persons for one year & $27.4 \mathrm{~kg} / \mathrm{person} /$ year \\
\hline
\end{tabular}

\subsection{Environmental Modules}

\section{(i) Waste Materials Flow Module}

The starting point for the model is the quantity and composition of waste managed by a municipality. A default composition for municipal solid waste has been included. It is strongly recommended that site specific waste composition data be used. This is because the composition of waste managed by a municipality will depend upon the programs in place in a given municipality. The default waste composition can be overwritten if the user municipality has site specific data available.

\section{Energy Module}

This module estimates the environmental burdens associated with the production, delivery and use of different forms of energy. Energy is consumed throughout the waste management system for transportation, material handling and processing. The production, delivery and use of this energy are major sources of a number of the pollutants considered in the model.

\section{(iii) Transportation Module}

The transportation module calculates the environmental burdens associated with: the collection, transfer and transportation of recyclables, compostables and garbage; the transportation of materials recovered at the MRF to markets; the transportation of MRF and compost residues to landfill or EFW; and, the 
Development of a Customized Integrated Waste Management Environmental Assessment (Iwmea) transportation of ash from EFW to landfill. The model provides default fuel efficiency values (Feff) of 1.25 $\mathrm{km} /$ litre for collection by diesel trucks (Olawoore, 2011).

(iv) Materials Recovery Facility (MRF) Module

The MRF module calculates the environmental burdens associated with MRF activities. These are essentially a function of the energy consumption, which is in turn dictated by the extent of mechanization. IWMEA Input Screen F will only appear if the user has entered a number greater than zero for 'quantity of waste recycled'.

(v) Materials Recycling Module

The module calculates the environmental burdens associated with the reprocessing that recovered materials have to undergo in order to be usable as substitutes for conventional materials (deinking, re-pulping, de-tinning, etc.). This module also evaluates the burdens avoided as a result of displacing virgin material ('offset burdens' or 'virgin material displacement credits'). The output of this module is a secondary source of information as it relates to activities outside the jurisdiction of the municipality. This module requires no input from the user.

\section{Energy from Waste Module}

The energy from waste module calculates the environmental burdens associated with recovering energy from a specified quantity of waste, based on the composition of the waste (and therefore its heat and carbon content), and data on air emissions, water effluents and solid residues. The input screen for energy from waste is shown in Figure 3 below

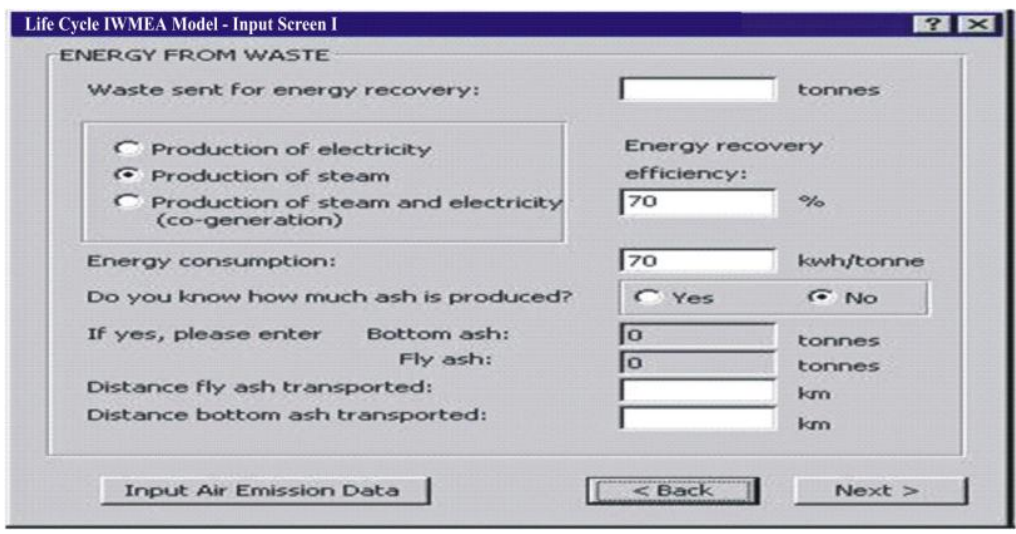

(vii) Landfill Module

Figure 3: Energy from Waste Input Screen

Based upon the characteristics of the landfill, the composition of the waste and the energy consumed in landfilling operations, the landfill module calculates the environmental burdens associated with: landfilling the quantity of waste specified by the user; and landfilling the residues from the other waste management practices selected. The input screen for landfilling is shown in Figure 4 below.

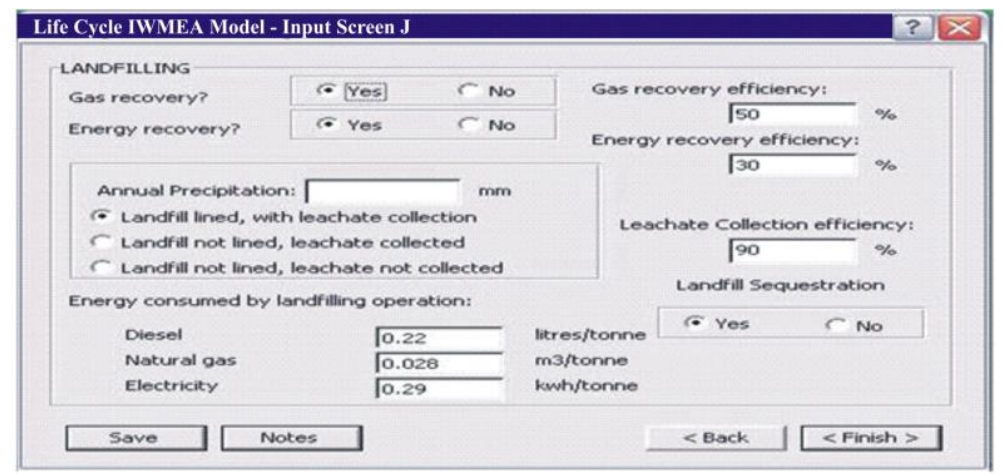

Figure 4: Landfilling Input Screen

\subsection{Application of the model at the Municipality of Ilorin, Nigeria}

The municipality of Ilorin is the capital of Kwara State with a population of 766,000 (NPC 2006), a surface of $100,000 \mathrm{~m}^{2}$ and $10,000 \mathrm{~km}$ of road network and that the city is increasing with annual rate of $1.5 \%$ population wise (Kwara State of Nigeria, 1997). By its tropical location, it has a temperature of about $27^{\circ} \mathrm{C}$ and annual rainfall of over $1000 \mathrm{~mm}$ (Olorunfemi and Odiata, 1998). It has two seasons, the wet and the dry seasons. 
Development of a Customized Integrated Waste Management Environmental Assessment (Iwmea)

The wet season last eight months, March to October that is the period of maximum solid waste generation while the dry season is from November to February with scanty rainfall (Adedibu, 1987; Awomuti, 1998; Olawoore, et. al 2011).

In Ilorin, there is only one waste recovery program and the program is widespread throughout the Ilorin metropolis since 2008 and are generally adopted by other municipalities. Ilorin has about 21 roro - bins (dumpsters placed by Kwara State Environmental Protection Agency (KWEPA) and about 108 roro - bins spatially distributed by O'lan Clean (KWMC) within Ilorin metropolis according to (Ajadi and Tunde, 2010). The contents of the bins are then transported for landfilling with no recovery rate. Olawoore et. al 2011, the estimated waste generation in the municipality of Ilorin in 2008 was $0.43 \mathrm{~kg} /$ person/day which was 0.15695 tonnes/person/year and the estimated waste generation in the municipality of Ilorin in 2009 was 219 $\mathrm{kg} / \mathrm{person} /$ day $(0.219$ tonnes/person/year), the waste generation in Ilorin is increasing with $40 \%$ and $1.5 \%$ for the $\mathrm{kg} / \mathrm{person} / \mathrm{day}$ rate and annual rate respectively. According to Olawoore et.al 2011, the program covered $59.611 \%$ of the population of Ilorin at year 2009 and will cover $90 \%$ of her population by the year 2019. In $2009,100,000$ tonnes of municipal solid waste were generated and but projected that with the above mentioned increase rate, in 2019 will be 116,000 tonnes. The waste composition in municipality of Ilorin in Figure 5 below.

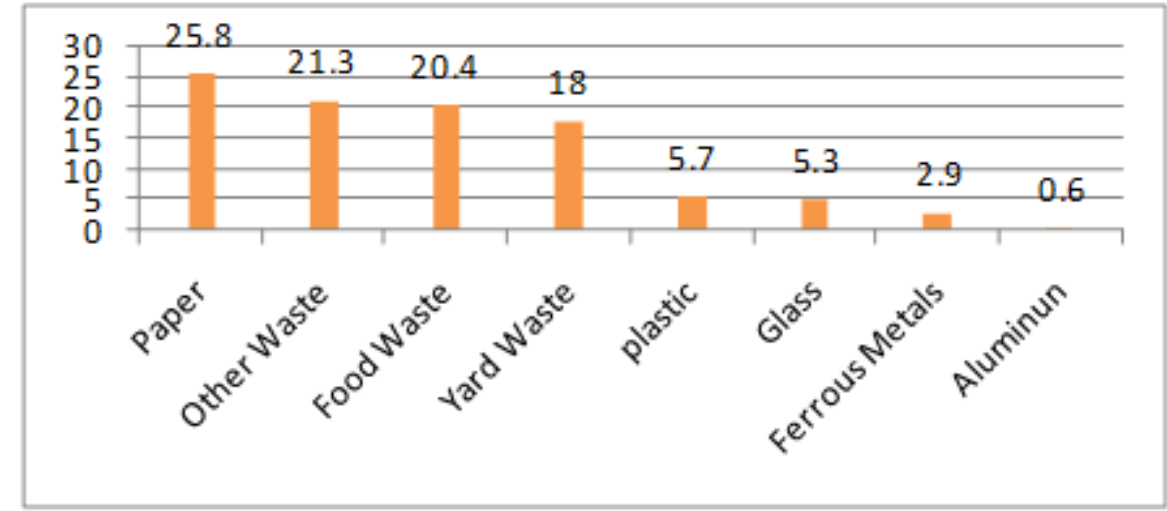

Figure 5: Ilorin Waste Composition 2009

Source: Olawoore, et. al 2011

Four different scenarios of waste management system were considered. Scenario one is such where all wastes (100,000 tonnes) are landfilled. This case represents the current status in Ilorin undertaken by Olawoore (2011); scenario two is $25 \%$ (25,000 tonnes) recycled, $75 \%$ (75,000 tonnes) landfilled; in scenario three we have $25 \%$ (25,000 tonnes) recycled, $20 \%$ (20,000 tonnes) composted, 55\% (55,000 tonnes) landfilled; scenario four has 25\% (25,000 tonnes) recycled, 20\% (20,000tonnes) composted, 20\% (20,000tonnes) EFW, 35\% (35,000tonnes) landfilled. Scenarios 2, 3 and 4 were fed to the IWMEA model in order to assess the possibility of improving the current MSWMS that exists in Ilorin municipality. The flow charts of the scenarios are given in Figure 6 (a-d) below.

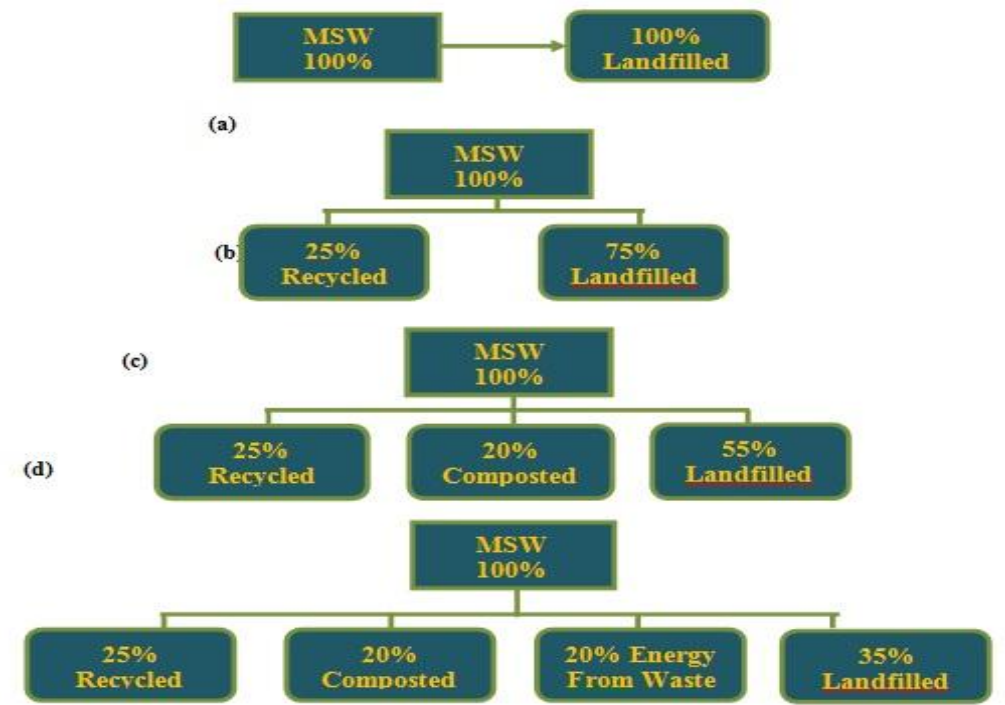

Figure 6. Flow charts of the scenarios (after efficiencies). (a) Scenario 1 (S1): 100\% landfilling. 
Development of a Customized Integrated Waste Management Environmental Assessment (Iwmea)

(a) Scenario 2 (S2): $25 \%$ recycling $+75 \%$ landfilling. (c) Scenario 3 (S3): $25 \%$ recycling $+20 \%$ composting $+55 \%$ landfilling. (d) Scenario 4 (S4): $25 \%$ recycling $+20 \%$ Composting $+20 \%$ energy from waste $+35 \%$ landfilling. (The percentages represent the proportion of the total municipal solid waste stream modelled.)

\section{III. $\quad 3.0 \quad$ Results and Discussion}

\subsection{Comparison of Environmental and Economical Impact Categories}

In order to ascertain the environmental burden associated with the various scenarios it is necessary to run the IWMEA model for each scenario. Although the IWMEA model tracks many environmental indicators the two which attract the most attention are "Energy Consumed" and "Greenhouse Gases". The precursors of smog are also briefly considered. Figures 7 and 8 illustrate the Energy consumed and Greenhouse Gas emissions from and by the waste management system. From the model results, most virgin materials are produced well beyond the boundaries of the community being studied. In all of the cases described above, all of the effects observed are local. This includes the displacement of energy from the provincial grid, all comparisons are made relative to the base case (i.e. scenario one).

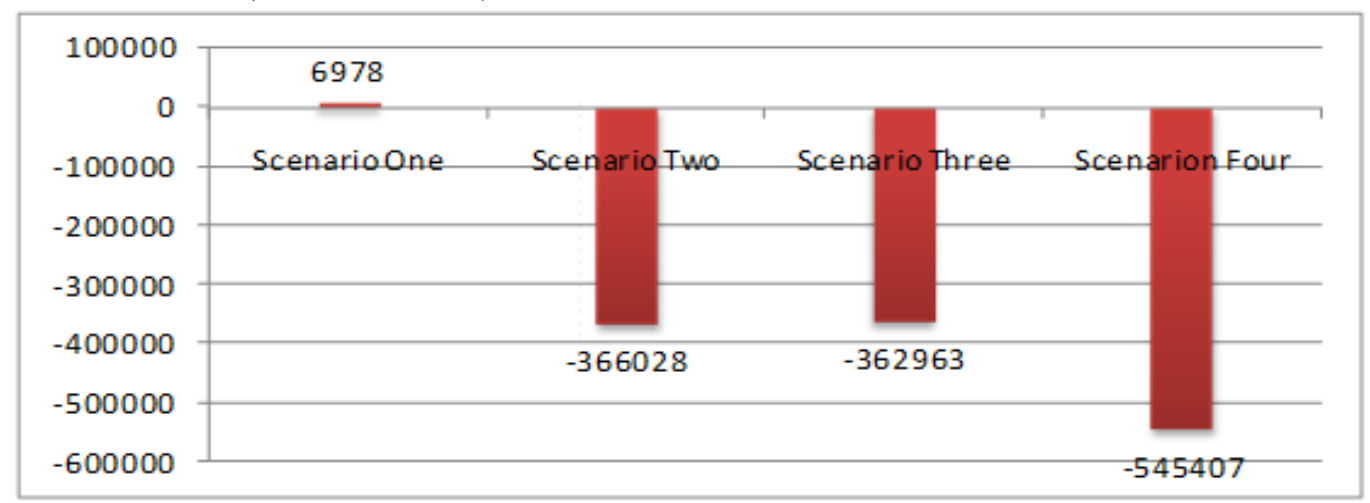

Figure 7: Energy Consumed by Waste Management System Gigajoules (GJ)

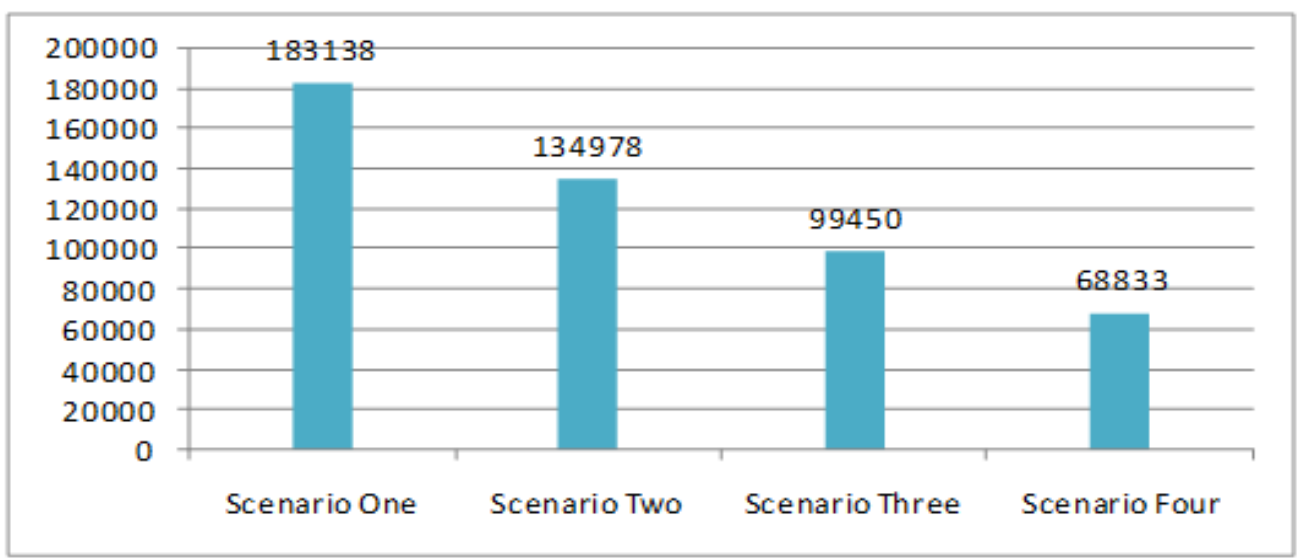

Figure 8: Greenhouse Gas Emissions from Waste Management System (tonnes $\mathrm{CO}_{2}$ equivalents)

\subsection{Energy Consumed and Reductions in Greenhouse Gas Emissions by scenarios}

\section{(i) Scenario One: All Waste (100,000 tonnes) Landfilled}

Even though landfilling may be publicly the most acceptable disposal method, there are a number of drawbacks. This scenario has been identified as having the highest environmental impacts compared to any other scenario. When all the waste generated were landfilled, the energy consumed is $6,978 \mathrm{GJ}$ and is equivalent to the annual consumption of electricity by 200 homes over the course of a year. In terms of greenhouse gas emissions there was no benefit. The GHG emission is 183,138 tonnes of $\mathrm{CO}_{2}$ equivalents which is the same as the emissions from 48,800 cars annually.

(ii) Scenario Two: $25 \%$ (25,000 tonnes) recycled, $75 \%$ (75,000 tonnes) landfilled

There was energy saving in this scenario due to a diversion of certain percentage of waste from landfilling to recycling which produces a benefit of 366,028 GJ. This is sufficient to cover all of the energy needs of the waste management operation and provide 330,724 GJ to the electrical grid. The benefit of this is 
Development of a Customized Integrated Waste Management Environmental Assessment (Iwmea) equivalent to the electricity used by 7,600 homes for one year. In terms of greenhouse gas emissions the benefit is not so impressive. GHG emissions are reduced by 48,160 tonnes to 134,978 tonnes of $\mathrm{CO}_{2}$ equivalents which is the same as the emissions from 36,600 cars for one year. The reason for the reduction in GHG emissions is due to the fact that certain percentage of waste was recycled instead of all waste been landfilled.

(iii) Scenario Three: $25 \%$ (25,000 tonnes) recycled, $20 \%$ (20,000 tonnes) composted, $55 \%(55,000$ tonnes) landfilled

In this scenario the energy saved is 362,963 GJ. This is sufficient energy to provide the annual electricity for 8,400 homes. Composting has a significant impact on GHG emissions in that emissions are reduced to 99,450 tonnes of $\mathrm{CO}_{2}$ equivalents each year. This result reflects the lower emissions of methane leaking from landfill and is equivalent to the emissions of 26,500 cars over the course of a year.

(iv) Scenario Four: $25 \%$ (25,000 tonnes) recycled, $20 \%$ (20,000 tonnes) composted, $20 \%$ (20,000 tonnes) EFW, 35\% (35,000 tonnes) landfilled

This scenario is similar to scenario three, except that instead of landfilling $55 \%$ of the waste we utilize $20 \%$ of it in energy from waste (EFW) process to generate electricity. In terms of energy consumed, this scenario saved 545,407 GJ of energy. The saved energy is so impressive and the benefit of this is equivalent to electricity for 12,600 homes for one year. The GHG emissions are reduced further by 114,305 tonnes of $\mathrm{CO}_{2}$ equivalent to 68,833 tonnes annually which is equivalent to the emissions from 18,400 cars.

\subsection{Smog Precursors}

SMOG: The oxides of nitrogen (NOx), volatile organic chemicals (VOC) and particulate matter (PM) react with ultraviolet light to produce what is commonly called "smog" - a health risk especially for the young and the elderly. Though truck traffic, landfill operations (e.g., dust, VOC emissions and combustion, waste management practices produce smog precursors. The IWMEA model measures the production of smog precursors and where appropriate applies credits against production for certain activities (such as reduction in vehicle traffic or, particularly, for recycling). Table 4 and Figure 9 summarize the reductions in smog precursors for the scenarios.

Table 4: Reductions in Smog Precursors (tones)

\begin{tabular}{|l|c|c|c|}
\hline Scenarios & NOx & Particulate Matter & VOCs \\
\hline ONE: All waste (100\%) landfilled. & 3.1 & 27.7 & 48.3 \\
TWO: 25\% recycled, 75\% landfilled. & -40.6 & -19.1 & 2.7 \\
THREE: 25\% recycled, 20\% composted, & -39.9 & -20.7 & -7.3 \\
\hline 55\% landfilled & -27.8 & -26.2 & -17.4 \\
FOUR: 25\% recycled, 20\% composted, & & & \\
\hline 25\% EFW, 30\% landfilled
\end{tabular}

Note: The NOx reductions for scenarios Four, Three and Two are all less than scenario one in which all waste were landfilled. This is due to the fact that all combustion processes utilizing air emit oxides of Nitrogen. All of the scenarios investigated achieved comparable reductions in NOx, particulate matter and VOCs.

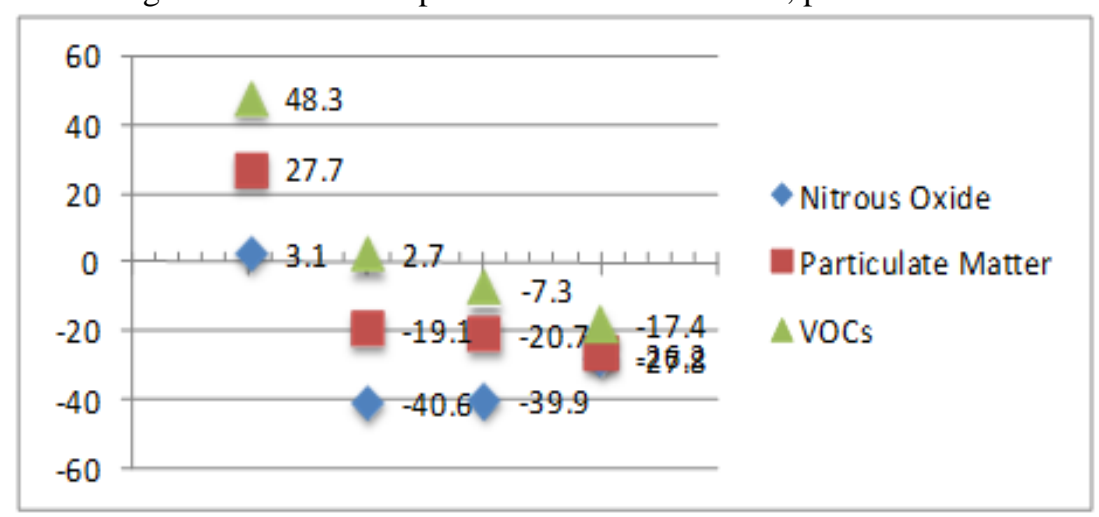

Figure 9: Reductions in Smog Precursors of the Scenarios

\subsection{Economical Impacts}

All the scenarios except scenario one include a significant amount of recycling. Naturally, therefore, each scenario offers energy savings. But the cost to implement each scenario differs substantially. Scenario One (100\% landfilled) costs the most. In fact, it costs $42.54 \%$ more than that of Scenario Four (25\% recycled, $20 \%$ 
Development of a Customized Integrated Waste Management Environmental Assessment (Iwmea) composted, $20 \% \mathrm{EFW}$ and 35\% landfilled). Table 5 lists the results. They are also illustrated graphically in Figure 10.

Note: The model calculates energy in the metric unit gigajoules (GJ). One barrel of crude oil is equivalent to $5.75 \mathrm{GJ}$.

Table 5: Energy Savings and Cost

\begin{tabular}{|l|c|c|c|}
\hline \multicolumn{1}{|c|}{ Scenario } & $\begin{array}{c}\text { Energy Saved } \\
\text { (GJ) }\end{array}$ & $\begin{array}{c}\text { Full Cost to } \\
\text { Manage Waste } \\
\text { (\$ Millions) }\end{array}$ & $\begin{array}{c}\text { Cost per GJ of } \\
\text { Energy Saved } \\
\text { (\$) }\end{array}$ \\
\hline ONE: All waste (100\%) & 6978 & 167.90 & $24,061.34 *$ \\
\hline landfilled. & 366,028 & 140.43 & 383.65 \\
TWO: 25\% recycled, 75\% landfilled & 362,963 & 118.45 & 326.33 \\
\hline THREE: 25\% recycled, 20\% composted, 55\% & & 96.47 & 176.87 \\
\hline landfilled & 545,407 & FOUR: 25\% recycled, 20\% composted, 25\% & \\
\hline EFW, 30\% landfilled
\end{tabular}

*Cost per GJ of Energy consumed

\begin{tabular}{|l|c|c|c|}
\hline \multicolumn{1}{|c|}{ Scenario } & $\begin{array}{c}\text { Greenhouse Gas } \\
\text { Reductions } \\
\text { (tonnes CO2 eqv.) }\end{array}$ & $\begin{array}{c}\text { Full Cost to } \\
\text { Manage Waste } \\
\text { (\$ Millions) }\end{array}$ & $\begin{array}{c}\text { Cost of } \\
\text { Greenhouse Gas } \\
\text { Reduction } \\
\text { (\$/tonne) }\end{array}$ \\
\hline $\begin{array}{l}\text { ONE: All waste (100\%) } \\
\text { landfilled. } \\
\text { TWO: 25\% recycled, 75\% }\end{array}$ & 183,138 & 167.90 & 916.80 \\
$\begin{array}{l}\text { landfilled } \\
\text { THREE: 25\% recycled, 20\% } \\
\begin{array}{l}\text { composted, 55\% landfilled } \\
\text { FOUR: 25\% recycled, 20\% } \\
\text { composted, 25\% EFW, 30\% } \\
\text { landfilled }\end{array}\end{array} \quad$ 69,450 & 140.43 & 1040.39 \\
\hline
\end{tabular}

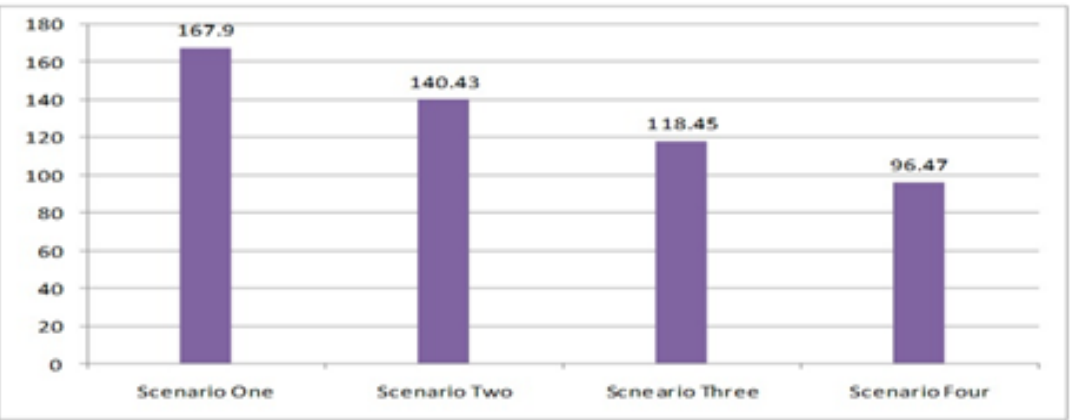

Figure 10: Full Cost to Manage Waste (\$ Millions)

Also every scenario affords a net reduction in greenhouse gas emissions, although at different costs. The results are exhibited in Table 6.

Table 6: Greenhouse Gas Reductions and Cost

\subsection{Policy implications}

In Ilorin, no LCA studies have been published in the past. More studies of this type must be conducted to establish a better understanding for the current pollution pool and MSW management systems. Also, LCA will lead to an establishment of databases that will aid decision makers and influential parties with environmental concerns.

Policy implications of obtained results usually depend on the aim of the policy itself

(Finnveden, Johansson, et al., 2005). Normally the aim of a policy is a combination of environmental and economical aspects. Results presented in this study promote a need for better treatment methods of MSW in Ilorin that can cope with the scale and magnitude of MSW fractions and MSWMS in the state. Considering scenario one as treatment of MSW in Ilorin, the waste treated will reduce the demand of energy from fossil fuel. Although oil is considered a cheap source of energy in Nigeria, waste can provide a better and more environmentally friendly energy source.

IV. Conclusion 
This study developed suitable scenario of waste management system in Ilorin municipality. IWMEA model of LCA was employed as a tool to compare different treatment options.

i. The IWMEA model of LCA solves the problem of imprecision and fuzziness involved in the solid waste decision-making process. In Scenarios Two 25\% (25,000 tonnes) recycled, 75\% (75,000 tonnes) landfilled, Three 25\% (25,000 tonnes) recycled, 20\% (20,000 tonnes) composted, 55\% (55,000 tonnes) landfilled, and Four Scenario Four: 25\% (25,000 tonnes) recycled, 20\% (20,000 tonnes) composted, 20\% (20,000 tonnes) EFW, 35\% (35,000 tonnes) landfilled there was energy savings of value $-366,028,-362,963$ and $-545,407$ GJ respectively while in Scenario One +6978 GJ of energy was consumed.

ii. Also, there was more reduction of greenhouse gases in Scenario Four as compared with Scenario Three, Two and One with different values of $+68,833 ;+99,450 ;+134,978$ and $+183,138$ GJ respectively.

iii. The more robust the management system the cheaper the cost. Scenario Four with even percentage of each management option was modelled to cost about $\$ 96.47$ million as against the $118.45,140.43$ and 167.90 million dollars for scenarios Three, Two and One respectively.

iv. Scenario Four has the least greenhouse gases emission, while the acid gas was best minimized in scenario Two. Scenario Three was however found to favour prevention of the heavy metal pollution.

iv. It is therefore recommended that scenario four, which represents a versatile, robust and least pollution-laden and cheapest option be employed for Ilorin municipality. Futher studies on implementation of IWMEA model in the Waste Management System of other developing regions are also suggested. V.

\section{References}

[1] Ajadi, B.S. and Tunde, A.M. "Spatial Variation in Solid Waste Composition and Management in Ilorin Metropolis, Nigeria". J Hum Ecol, 32(2): 101-108. 2010.

[2] Aumonier, B. "Life Cycle Analysis of Waste Streams". Presented at the Fourth Annual Conference on Incineration, Towards a Waste Management Strategy. 8-9 February 1995.

[3] Adedibu, A.A. "Spatial Pattern of Solid Waste Generation in the Third World Countries: A Case study of Ilorin, Nigeria". Third World Planning Review, 5(2): 136-143. 1983.

[4] Adedibu, A.A. "Measuring Waste Generation in Third World Cities. A case study of Ilorin, Nigeria". Environmentalist, pp. $20-23$. 1987.

[5] Awomuti, A.A. "An Analysis of Waste Generation Rate and Pattern in Ilorin, Nigeria". Lapai International Journal of Management and Social Sciences, 1(1): 171- 183. 2008

[6] Badran, M.F. and El-Haggar, S.M. "Optimization of Municipal Solid Waste Management in Port Said - Egypt". Waste Management 26, 534-545. 2006.

[7] Caruso, C., Colorni, A., Paruccini, M., "The regional urban solid waste management system: A modelling approach". European Journal of Operational Research 70, 16-30. 1993.

[8] Chang, N.B., Chen, Y.L., Wang, S.F. “A Fuzzy Interval Multi objective Mixed Integer Programming Approach for the Optimal Planning of Solid Waste Management Systems". Fuzzy Sets and Systems 89, 35-60. 1997.

[9] Chang, N.B., Wang, S.F. "Solid Waste Management System Analysis by Multi objective Mixed Integer Programming Model". Journal of Environmental Management 48, 17-43. 1996.

[10] Costi, P., Minciardi, R., Robba, M., Rovatti, M., Sacile, R. "An environmentally sustainable decision model for urban solid waste management". Waste Management 24, 277-295. 2004.

[11] Finnveden, G., Johansson, J., Lind, P., Moberg, A. "Life cycle assessment of energy from solid waste-part 1: general methodology and results". Journal of Cleaner Production, 13, pp. 213-229. 2005.

[12] Chandler, A.J.. Municipal Solid Waste Incineration Technologies, Education Program Innovations Centre Inc. Seminar, April 1997.

[13] Environment Canada, Options for Managing Emissions from Solid Waste Landfills. Prepared by Hickling and Emcon Associates. 1994.

[14] Environmental Agency. Life Cycle Inventory Development for Waste Management Operations: Composting and Anaerobic Digestion. 59 pages and Appendices. Bristol, U.K. 2000.

[15] ISO (International Standards Organization) no. 14040. Environmental management- Life Cycle Assessment: Principles and framework, Geneva, Switzerland.

[16] Kwara State Management Council. 2nd phase of Green/Clean-Campaign Booklet. 2007. Kwara State of Nigeria. Kwara State Diary, Government Press, Ilorin, Nigeria. 1997

[17] McDougall, F., White, P., Franke, M., Hindle, P. Integrated Solid Waste Management: A Life Cycle Inventory. 2nd Edition. Published by Blackwell Science Ltd., Oxford, U.K. 2001.

[18] Morrissey, A.J. and Browne, J. "Waste management models and their application to sustainable waste management". Waste Management 24, 297-308. 2004.

[19] National Population Commission. Population Figures, Kwara State. 2006

[20] Olorunfemi, J.F. and Odiata, C.O. "Land use and solid waste generation in Ilorin, Kwara State". The Environmentalists. 2: 67-75. 1998.

[21] Olawoore, I.O, Adegbola, A.A, Ojoawo, S.O and Olaniyan, O.S. "Development of a customized environmental Assessment model for integrated waste management (EAMIWM)". Book of Abstract. Alexander von Humboldt Conference, University of Ibadan, Ibadan. October 11-15, pp 36-37. 2011

[22] Society of Environmental Toxicology and Chemistry (SETAC),. A Technical Framework for Life Cycle Assessment. SETAC. Penascola, Florida. 1991.

[23] U.S. EPA,. Demonstrating Leachate Treatment: Report on a Full Scale Operating Plant Report SW-758. 1979

[24] U.S. EPA,. Compilation of Air Pollutant Emission Factors, Volume 1: Stationary Point and Area Sources. Draft: Municipal Waste Landfills. 1995. 